\title{
Os usuários da informação jurídica
}

\author{
Fabio Assis Pinho \\ Universidade Federal de Pernambuco - Brasil \\ Ângela Maria da Silva Barbosa \\ Universidade Federal de Pernambuco - Brasil
}

ESTUDO / CASE

\section{Resumo}

A tomada de decisões necessita estar embasada em informações atuais e confiáveis, especialmente, nos ambientes jurídicos. No Brasil, as mudanças na legislação são constantes motivadas principalmente pelas promulgações de medidas provisórias. Neste sentido, faz-se necessário conhecer bem as fontes e as mudanças para satisfazer as necessidades dos usuários da área jurídica. Por isso, através de uma pesquisa exploratória, cujo objetivo foi realizar um estudo de usuários, especialistas na área jurídica, na biblioteca da Procuradoria Regional da República da $5^{\underline{a}}$ Região (Brasil), que é uma unidade que pertence ao Ministério Público Federal do Brasil, usando o questionário como ferramenta de coleta de dados. Os resultados mostraram que os usuários da informação jurídica são exigentes e específicos em suas pesquisas, realizando buscas em diferentes fontes de informação, uma vez que suas necessidades apresentam um grau elevado de dificuldade.

Palavras-chave

Estudos de usuários; Necessidade informacional; Bibliotecas especializadas; Informação jurídica

\section{The users of legal information}

\begin{abstract}
The decision making needs must be based on current and reliable information, especially in legal environments. In Brazil, the changes in legislation are constants because of the enactments of the provisional measures. In this sense, it is necessary to know the sources and changes to satisfy the needs of users of legal area. Therefore, through an exploratory research, it aimed to do a user study, experts on legal aspects in the law library of the Regional Procurator of the Republic of the 5th Region (Brazil), which is a unit belonging to Brazil's Federal Public Ministry, with the use of a questionnaire as data collection tool. The results shows that users of legal information is more demanding and expert in their search and uses various sources, because their information needs has a high degree of difficulty.
\end{abstract}

Keywords

User studies; Information needs; Special libraries; Legal information

\section{Introdução}

As bibliotecas e centros de documentação que lidam com a informação jurídica possuem nuances bem peculiares no desenvolvimento de suas atividades, sendo o caráter dinâmico da informação jurídica o que mais influencia nas rotinas. No Brasil, devido às constantes alterações na legislação, a doutrina e a jurisprudência também sofrem mudanças significativas em pouco tempo. Isso afeta toda a cadeia produtiva da informação jurídica e reflete nas bibliotecas da área, que em sua maioria pertencem à esfera pública. Esse universo torna o processo de seleção e 
desenvolvimento de coleções uma área estratégica exigindo toda atenção por parte dos bibliotecários. Dessa maneira, a realização de estudos de usuários é o meio mais adequado de suporte a tomada de decisão pela gestão de bibliotecas no momento de planejar novas estratégias de atendimento às consultas bem como se antecipar às novas demandas. O gestor deve levar em consideração as características e os comportamentos dos usuários em todos os momentos.

No âmbito da Ciência da informação, usuário é todo indivíduo que busca por uma informação ou serviço em uma unidade ou sistema de informação, em qualquer meio que ele possa ter disponibilidade. Os usuários reais são os que de fato interrogam o sistema num dado momento, mas existem também os usuários potenciais que são aqueles que preenchem todos os requisitos para utilizar a unidade de informação e não o fazem nunca, ou pelo menos não com tanta frequência. Segundo Dias e Pires (2004, p. 9), os não-usuários incluem aqueles que desconhecem os serviços ou como utilizá-los, os que não confiam nos serviços bem como os que não têm consciência que possuem necessidades de informação.

Nesse sentido, a necessidade informacional é o foco deste trabalho, além das variáveis que o tema envolve. De acordo com Nascimento e Weschenfelder (2002, p. 322), "entende-se por necessidade de informação, a carência de informação que o indivíduo deve suprir para realizar uma pesquisa, para sua educação e atualização pessoal, ou para uma tomada de decisão em seu desempenho profissional".

Estudos para conhecer, analisar e avaliar as comunidades consumidoras de informação de um determinado sistema é uma área estudada pela Biblioteconomia e da Documentação Científica desde os anos de 1940 no Brasil.

Figueiredo (1994, p. 7) afirma em um dos conceitos sobre esses estudos que:

"estudos de usuários são investigações que se fazem para saber o que os indivíduos precisam em matéria de informação, ou então, para saber se as necessidades de informação por parte dos usuários de uma biblioteca ou de um centro de informação estão sendo satisfeitas de maneira adequada".

Sob esse aspecto, Sanz Casado (1994, p. 30) afirma que os estudos de usuários são "um conjunto de estudos que tratam de analisar, qualitativa e quantitativamente, os hábitos de informação dos usuários sobre seu consumo de informação". Estes estudos podem ser realizados através de instrumentos de coleta como os questionários, as entrevistas e outros.

O questionário é a técnica mais utilizada para a coleta de dados seguida da entrevista, além do sense-making, por exemplo. O questionário além de garantir o anonimato dos respondentes tem um alcance maior devido ao fato de poder ser enviado por correio eletrônico ou impresso e entregue a várias pessoas ao mesmo tempo. No entanto a entrevista, por ter a aplicação assistida pelo responsável que está conduzindo o estudo, pode elucidar dúvidas sobre as questões. Enquanto que no caso do uso de questionário sempre ficam dúvidas se a questão foi de fato entendida pelo usuário. No entanto, para solucionar essa problemática, faz-se necessário aplicar um pré-teste do instrumento de coleta de dados em uma comunidade semelhante àquela investigada, fato que ocorreu neste artigo.

Além dos usuários especialistas existem também as bibliotecas ou os centros de documentação especializada na área jurídica, que mantêm em suas coleções e bases de dados uma série de informações sobre leis, legislação, jurisprudência, pareceres e outras que ao longo deste artigo serão denominadas de informação jurídica. Segundo Passos e Barros (2009, p. 94) a informação jurídica "pode ser gerada, registrada e recuperada, basicamente, em três formas distintas: analítica (por meio da doutrina); normativa (pela legislação) e interpretativa (com o emprego da jurisprudência)".

No Brasil, as bibliotecas ou centros de documentação jurídica são, em sua maioria, unidades de informação que fazem parte de órgãos públicos das três esferas (federal, estadual e municipal) e estão ligados a órgãos do Legislativo, do Executivo, do Judiciário e também do Ministério Público. Os arquivos judiciais também constituem importantes fontes de informação jurídica em razão do caráter probatório dos documentos que mantêm. Há ainda as 
bibliotecas das instituições de ensino superior que mantêm cursos de direito e as dos escritórios de advocacia que também são consideradas unidades de informação jurídica.

O maior desafio dessas bibliotecas hoje em dia é manter atualizados seus acervos face ao aspecto dinâmico com que a informação jurídica é gerada e consumida no Brasil. As mudanças se iniciam na legislação e trazem consigo as modificações na jurisprudência e na doutrina.

Neste sentido, levando em consideração as necessidades de informação dos profissionais que trabalham nos tribunais e nas procuradorias como, por exemplo, advogados, juízes, escrivães, tem-se o objetivo de apresentar os resultados de um estudo de usuários, especialistas na área jurídica, realizado na biblioteca da Procuradoria Regional da República da 5aㅗ Região, que é uma unidade que pertence ao Ministério Público Federal do Brasil.

\section{Material e Método}

A pesquisa realizada caracteriza-se como exploratória porque traz em seu bojo a necessidade de familiarizar-se com o fenômeno. Dessa maneira, a pesquisa exploratória está baseada em um estudo de caso, utilizando como população-alvo os usuários da biblioteca da Procuradoria Regional da República 5a Região, sendo eleito o questionário como instrumento de coleta de dados.

\subsection{Caracterização da Instituição Pesquisada}

Com a criação das procuradorias regionais da República, em 1992, a Procuradoria Regional da República 5ª Região iniciou sua estruturação e as atividades da biblioteca, especializada em Direito e áreas afins, tem como missão dar suporte às atividades dos procuradores, servidores e estagiários que lá atuam. Em 1997 passou a se chamar Biblioteca Professor Everardo da Cunha Luna que, atualmente, ocupa o andar térreo da procuradoria em ambiente planejado e compatível com as suas atividades.

O espaço físico dessa unidade de informação inclui balcão de recepção, sala de pesquisa, sala de processos técnicos, sala da chefia, área do acervo e salão de leitura, sala de estudo individual composto por quatro cabines sala de estudo em grupo, dispostos numa área de aproximadamente $165 \mathrm{~m}^{2}$.

Nos acervos estão disponíveis para consulta documentos como livros, periódicos, jornais, diários oficiais, que estão dispostos em módulos de estantes deslizantes que além de aproveitar o espaço físico emprestam beleza e modernidade ao ambiente. O acervo possui ainda CD's, DVD's e fotografias. A biblioteca integra a Rede de Bibliotecas do Ministério Público Federal (RBMPF) formada por 37 unidades do Ministério Público Federal que iniciaram, em 2005, a utilização do Sistema Pergamum para gerenciamento do acervo. A equipe da biblioteca é formada por três bibliotecários, dois técnicos administrativos e três estagiários de Biblioteconomia. O horário de funcionamento para atendimento dos seus usuários é das $8 \mathrm{~h}$ às 19h, de segunda a sexta-feira.

\subsection{População-Alvo Pesquisada}

A população estudada é formada pelos usuários da biblioteca da Procuradoria Regional da República 5aㅡ Região que é composta por 19 procuradores regionais da República, 143 servidores e 47 estagiários. De um total de 209 usuários, deve-se considerar que existe um percentual que atua na área meio o que diminuiu a frequência à biblioteca, uma vez que se trata de uma unidade de informação especializada na área jurídica.

\subsection{Instrumento de Coleta de Dados}

O instrumento escolhido para coleta dos dados foi um questionário composto de 27 questões fechadas e duas abertas. A aplicação dos questionários ocorreu no período de 18 de junho 2009 a 30 de setembro de 2009.

O procedimento de entrega do questionário foi através da abordagem do usuário na biblioteca após suas consultas efetuadas. Além disso, foi realizado o envio de questionários por correio eletrônico, com duas mensagens. A 
primeira no dia 18 de junho, no início da pesquisa, e a outra mensagem no final do mês de agosto. Durante todo o período de coleta, foi oferecido aos usuários o questionário no momento das consultas in loco.

A análise dos dados foi feita utilizando estatística simples para as questões fechadas e análise de conteúdo para as questões abertas.

\section{Análise e discussão dos resultados}

Foram recebidos 58 questionários o que representa $28 \%$ do total de 209 usuários potenciais. Destes 49 foram entregues impressos e nove retornaram por correio eletrônico.

A primeira questão envolveu a categorização da população estudada. Os usuários da Procuradoria Regional da República 5a Região encontram-se divididos em procuradores regionais, servidores e estagiários. Inicialmente o estudo procurou investigar a qual categoria o usuário pertencia. Dos 58 questionários recebidos, 33 foram de servidores, 23 de estagiários e dois de procuradores regionais. Considerando-se o total por categoria tem-se a representação das respostas no gráfico 1.

\section{Categoria dos usuários}
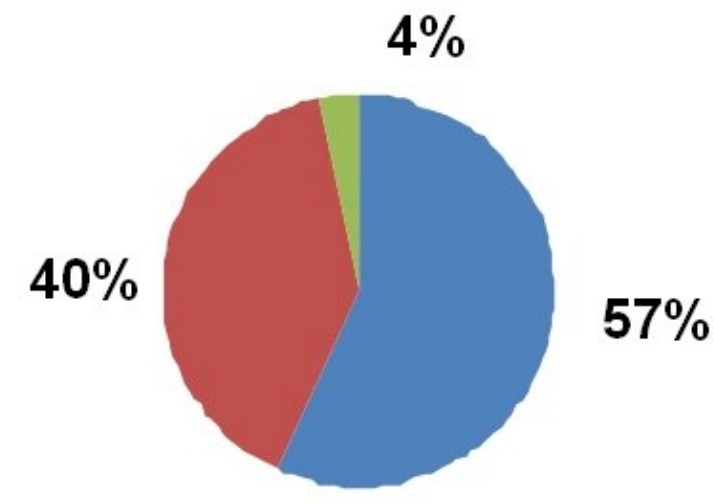

Servidor

Estagiário

Procurador

\section{Gráfico 1 - Categoria dos usuários.}

$\mathrm{Na}$ questão seguinte, quando se perguntou sobre a periodicidade média de frequência na biblioteca, os resultados demonstraram que a maioria dos respondentes, 25, o faz uma vez por semana (42\%). Além disso, 18 afirmaram frequentar 3 vezes por semana (31\%) e 9 usuários o fazem diariamente (16\%). A opção '2 vezes por mês' foi escolhida por 5 pessoas $(9 \%)$ e uma pessoa deixou de marcar esta resposta (2\%). Para uma melhor visualização foi preparado o gráfico 2. 


\section{Frequência na Biblioteca}

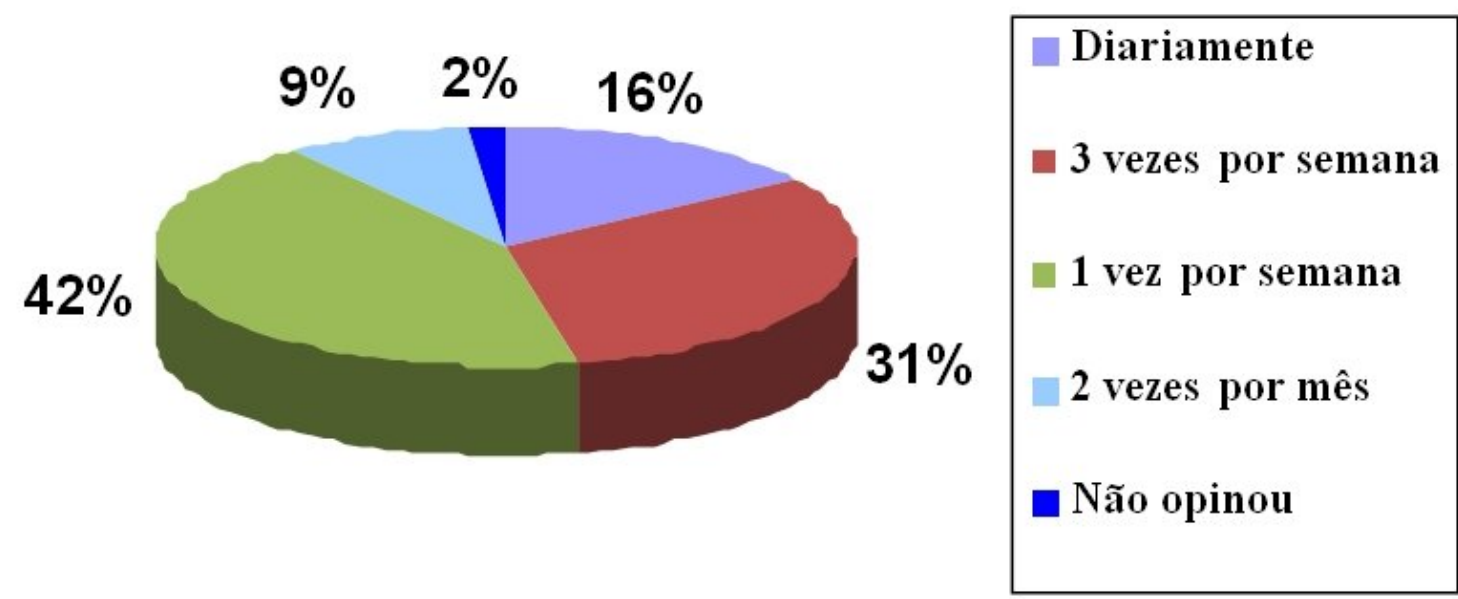

Gráfico 2 - Frequência na biblioteca

A terceira pergunta do questionário interessou-se por verificar qual o recurso do acervo mais utilizado pelos usuários. O gráfico 3 apresenta as respostas referentes ao que foi perguntado nesse momento.

\section{Recurso mais utilizado}

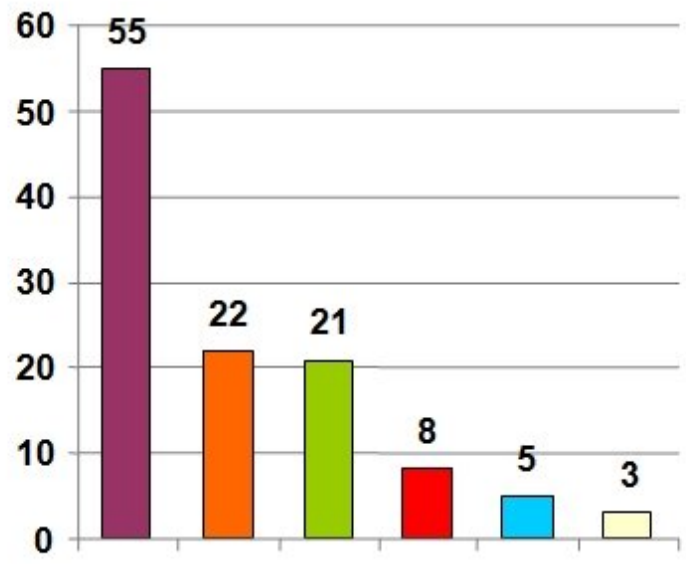

Doutrina

Jurisprudência

Legislação federal

Normas MPF

Pareceres

Legislação de outras instituições 
Vários usuários assinalaram mais de uma resposta e conforme se pode observar, a doutrina foi a que ficou em primeiro lugar tendo sido assinalada por 55 usuários do total de 58 questionários devolvidos. Jurisprudência (22), Legislação federal (21), Normas internas do Ministério Público Federal (8), Pareceres (5) e Legislação referente a outras instituições (3) foram os recursos mais destacados. É necessário salientar que duas pessoas assinalaram todas as opções e uma deixou a questão em branco.

Além disso, no espaço reservado para citar outros recursos, dois usuários optaram por jornais e um citou 'revistas jurídicas' apesar de estas serem um suporte que pode conter doutrina, jurisprudência etc. A constatação de uma preferência pela doutrina não é uma surpresa nesse estudo devido à confiabilidade das fontes eletrônicas da legislação e jurisprudência que, em geral, são publicadas em sites de instituições do legislativo e do judiciário.

A questão 4 abordou as fontes de informação e perguntou qual ou quais outras fontes, além da biblioteca, são utilizadas no desempenho do trabalho dos usuários. Sabe-se que as fontes informais tais como colegas de profissão podem ser tão ou mais valiosas para o usuário que mesmo as bibliotecas ou banco de dados on-line (CHOO, 2006, p. 79).

No caso específico dessa pergunta, a pesquisa na internet em sites de busca ficou em primeiro lugar, tendo sido marcada por 53 respondentes. As bases de dados especializadas tais como as do Senado Federal e do Planalto (Presidência da República) foram as opções assinaladas por 36 participantes. A consulta a um colega de profissão é utilizada por 20 dos respondentes, enquanto 24 também pesquisam em seus acervos particulares ou em livros e documentos existentes no próprio setor. O gráfico 4 representa o resultado obtido.

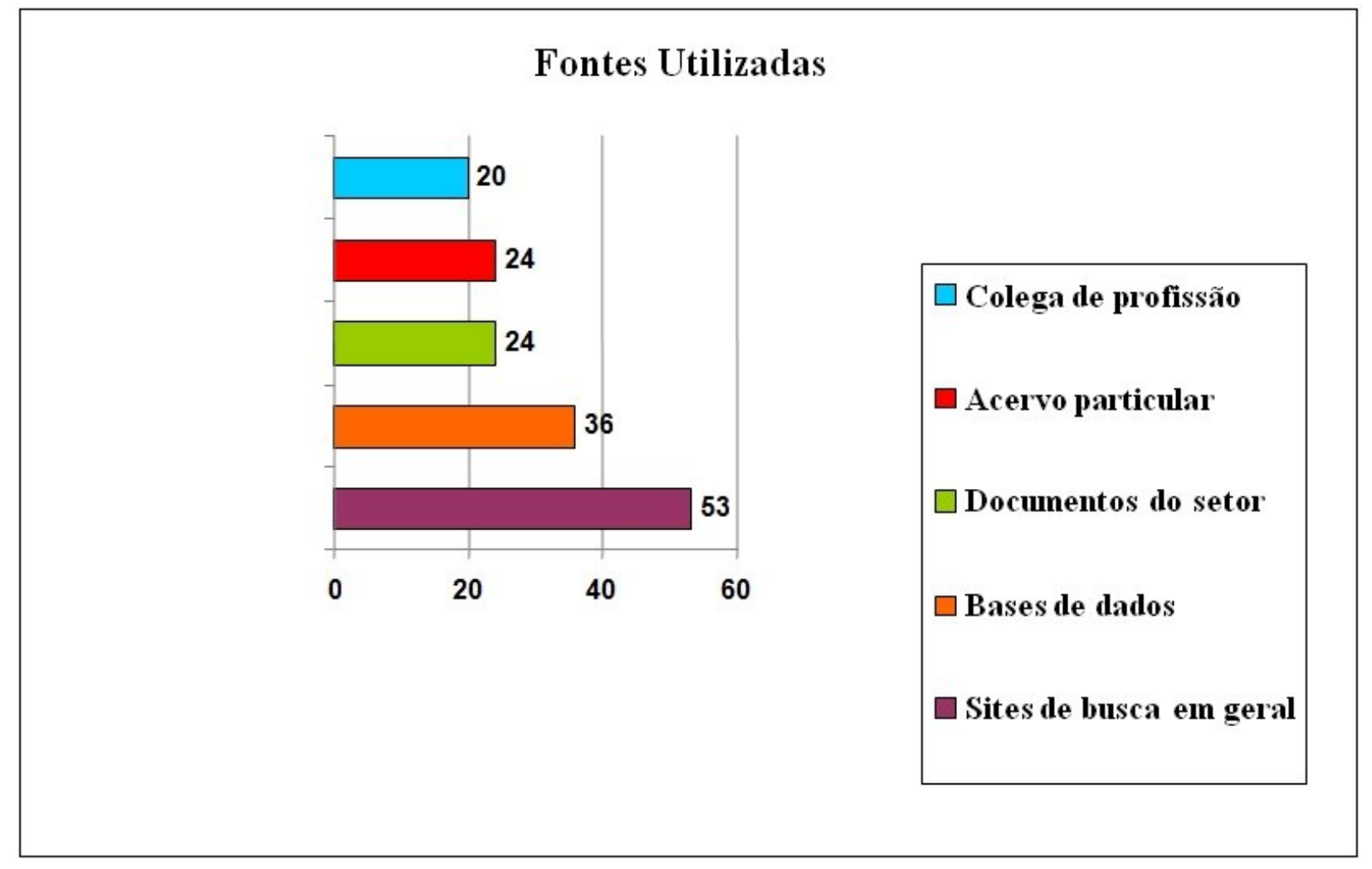

Gráfico 4 - Fontes utilizadas para buscar informação 
Ainda sobre a questão 4, verificou-se que 10 pessoas assinalaram todas as opções o que demonstra um caráter de exaustividade no comportamento de busca desses usuários. No espaço livre para citação de algum outro recurso uma pessoa citou o sistema de gestão de pareceres de procuradores utilizado na Procuradoria Regional, uma fonte específica e interna.

A questão 5 buscou saber em que momento o usuário pensa em procurar a biblioteca. Vinte e oito responderam que é após pesquisar em fontes eletrônicas disponíveis na internet. Quatorze pessoas responderam que pensam na biblioteca assim que precisam de alguma informação, 13 marcaram a opção que é quando acham que a informação será mais confiável e 11 quando já buscaram em fontes bibliográficas. Oito afirmaram que procuram a biblioteca quando estão em dúvida sobre o assunto pesquisado. A representação dos números sobre a questão 5 está disposta no gráfico 5 .

\section{Momento em que necessita da Biblioteca}

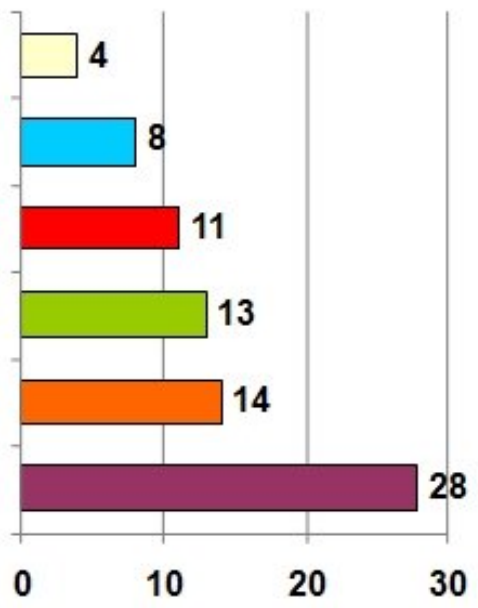

$\square$ Precisa com urgência

$\square$ Está em dúvida

Já buscou fontes

bibliográficas

$\square$ Quando necessita de

Confiabilidade

Logo que precisa

Já buscou na Internet

\section{Gráfico 5 - Momento em que necessita da biblioteca}

A questão 6 perguntou para que os usuários utilizam a biblioteca da Procuradoria, ou seja, a finalidade. As respostas mostraram que 48 dos respondentes utilizam-na para o trabalho, seguido dos que o fazem por necessidade pessoal de aumentar seus conhecimentos (32) e depois daqueles que fazem uso como complemento para seus estudos de nível superior (25). A motivação para estudar para concursos foi marcada por 24 pessoas e 19 afirmaram utilizá-la para leitura de jornais. É importante salientar que nove usuários assinalaram todas as opções. Os números podem ser visualizados no gráfico 6. 


\section{Utilização da Unidade de Informação}

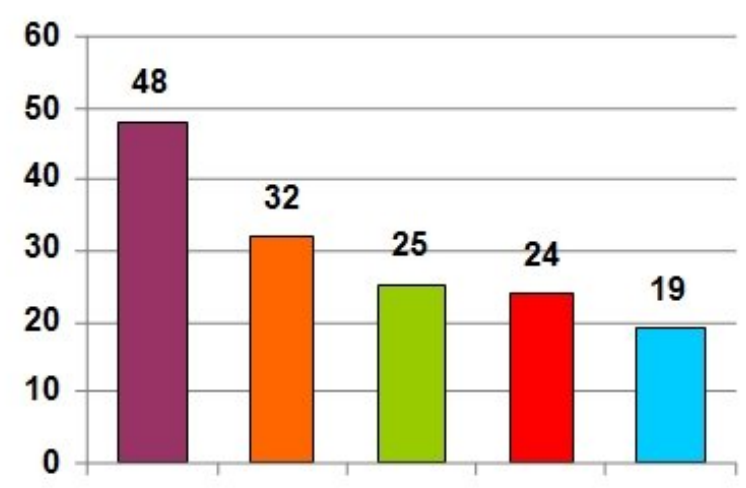

\begin{tabular}{|l|}
\hline Trabalho \\
$\square$ Aumentar seus \\
conhecimentos \\
$\square$ Complemento à \\
Faculdade \\
$\square$ Concursos \\
$\square$ Leitura de jornais
\end{tabular}

Gráfico 6 - Utilização da unidade de informação

Na questão 7 que investigou a autonomia dos usuários no uso da unidade de informação foi perguntado se eles costumam solicitar ajuda de um servidor ou estagiário da biblioteca na busca pela informação. Os resultados mostraram que 50 respondentes solicitam apenas às vezes perfazendo um total de $86 \%$. Os que afirmaram pedir ajuda sempre foram sete (12\%) e apenas um usuário (2\%) nunca solicitou auxílio. Os resultados podem ser visualizados no gráfico 7.

A questão 8 do instrumento de coleta de dados procurou descobrir qual a modalidade da informação jurídica mais buscada pelos usuários e as respostas demonstraram a unanimidade na busca pela doutrina jurídica presente em livros, uma vez que, 56 usuários assinalaram essa resposta. A doutrina em periódicos foi escolhida por sete respondentes e a legislação por cinco.

A jurisprudência não foi escolhida por ninguém e uma pessoa optou por deixar a questão em branco. Apesar do objetivo dessa questão ser a escolha de apenas uma opção, um usuário marcou doutrina em livros, periódicos e legislação, três marcaram doutrina em livros e legislação e seis marcaram doutrina em livros e periódicos. Tais resultados, que figuram no gráfico 8, podem contribuir para justificar a não aquisição de suportes da informação que contenham apenas jurisprudência uma vez que percebe-se a inexistência de consultas a essa modalidade de informação jurídica no âmbito da biblioteca. 


\section{Solicitação de auxílio}

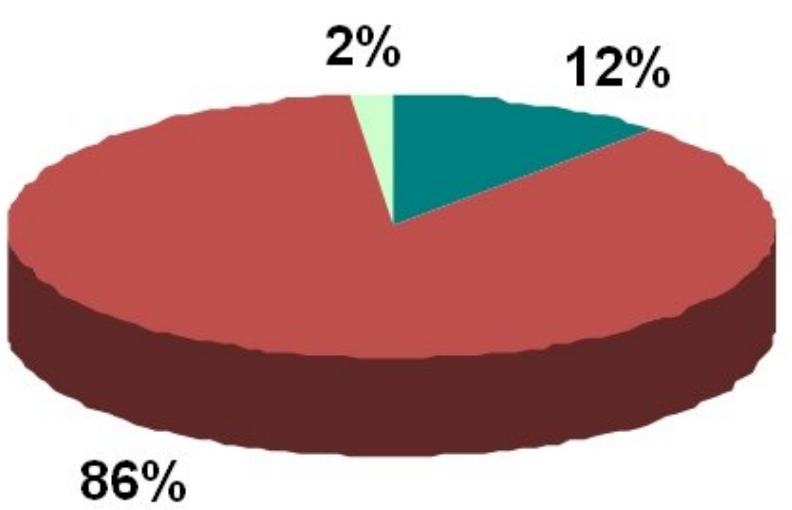

Sempre

Às vezes

Nunca

\section{Informação jurídica de maior interesse}

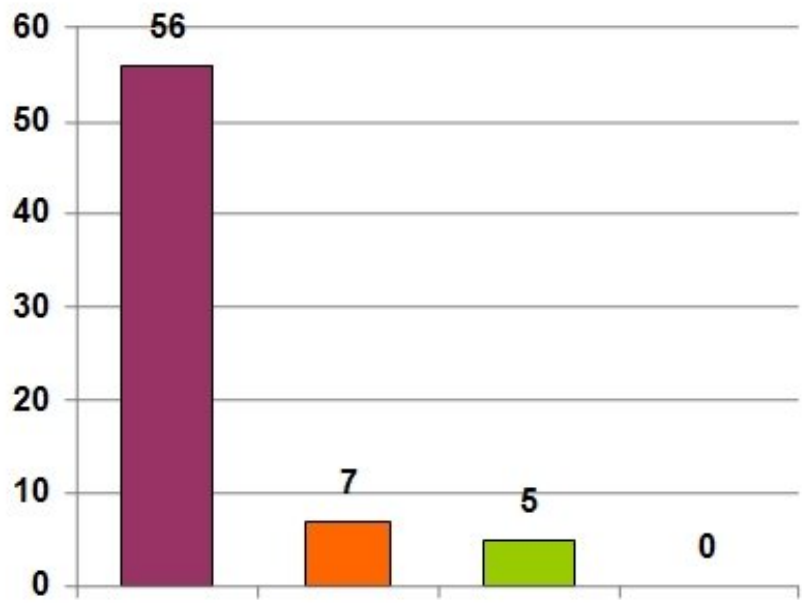

Doutrina em livros

Doutrina em periódicos

$\square$ Legislação

Jurisprudência 
$\mathrm{Na}$ questão 9 foi perguntado com qual freqüência o usuário encontra o que procura na biblioteca. Trinta e um responderam 'sempre'. Já a resposta 'às vezes' foi opção de 24 pessoas enquanto 'nunca' não foi assinalado por nenhum usuário. Verificou-se que duas pessoas criaram uma nova opção intitulada 'quase sempre' e a marcaram. Enquanto que cinco usuários acrescentaram a palavra 'quase' antes da opção sempre antes de marcá-la. Um usuário deixou essa resposta em branco.

Nas questões 10 a 25 procurou-se avaliar o índice de satisfação para com a unidade de informação conforme os recursos de pessoal, acervo e meio ambiente da biblioteca bem como avaliar os serviços de atendimento e circulação da unidade de informação. Os resultados demonstraram que $86 \%$ dos participantes da pesquisa concordam que o serviço é prestado de forma imediata ao usuário, $74 \%$ concordaram que seus questionamentos são atendidos satisfatoriamente.

Além disso, procurou-se identificar a familiaridade dos pesquisados em relação às fontes de informação eletrônicas e o resultado para essa familiaridade foi de $66 \%$. Nas questões 13 e 14, que procuraram medir a satisfação do usuário em relação à quantidade e qualidade do acervo. Observou-se que a satisfação com a quantidade e a qualidade do acervo bibliográfico apresentou respostas equilibradas pelos usuários, tendo sido inclusive utilizada a opção 'Discordo totalmente' tanto na questão 13 quanto na 14. Deixaram de opinar uma pessoa quanto à quantidade e duas quanto a qualidade. Contudo a maioria dos usuários marcou a opção 'Concordo parcialmente' na afirmativa que se refere à qualidade do acervo (para efeitos desta pesquisa relacionada à atualização).

A questão 15 investigou se os usuários utilizam e se estão satisfeitos com o catálogo eletrônico da biblioteca, que no caso é gerenciado através do Sistema Pergamum. As respostas obtidas revelaram que 32, ou seja, $60 \%$ concorda totalmente que a pesquisa recupera documentos relevantes em relação às buscas formuladas. Dezessete $(31 \%)$ concordam parcialmente com a afirmativa proposta e quatro (7\%) discordam parcialmente desta. Uma pessoa (2\%) marcou a opção 1 para representar sua opinião. Fato interessante é que quatro pessoas deixaram de assinalar qualquer uma das alternativas, o que pode indicar desconhecimento do catálogo on-line ou mesmo inabilidade em utilizá-lo.

As questões 16 e 17 versaram sobre a circulação de materiais na unidade de informação e buscaram investigar o grau de satisfação com relação ao prazo e ao quantitativo de itens permitido por usuários. Vale salientar, que conforme o regulamento da Biblioteca vigente (Portaria PRR5 oㅜ 33, de 5 de novembro de 2007) e disponível na seção da biblioteca e em seu site, o prazo de empréstimos é único (7 dias) para servidores e estagiários enquanto que para procurador é de 45 dias. A quantidade de itens permitida para estagiários é de quatro livros, para servidores de seis livros e para procuradores o número é ilimitado em razão de que estes são membros da instituição.

Nas questões de número 18 a 25 procurou verificar a satisfação com relação ao bem estar e as instalações da biblioteca. Os resultados demonstraram que os usuários estão satisfeitos com a adequação das estantes, com a localização do material e com o espaço físico disponibilizado para leitura. Além disso, os pesquisados estão satisfeitos com as salas de estudo, com a climatização, com a iluminação e com a limpeza.

Quanto à questão totalmente aberta, de número 26, que perguntou 'O que você gostaria que mudasse na Biblioteca'. Dentre os que responderam, muitos citaram mais de um item que gostaria que mudasse na biblioteca, como por exemplo, a acústica e a circulação de material. Vinte e oito usuários citaram a necessidade de melhorar a acústica na biblioteca como forma de aperfeiçoar o ambiente para estudos. Foi sugerida a ampliação do acervo de um modo geral, do acervo de livros mais atualizados e do acervo de exemplares mais procurados, melhor acervo de obras de estudo para concursos; periódicos, códigos jurídicos e literatura como forma de incentivo a leitura. Em seguida aparecem as sugestões de ampliação do espaço como um todo e do espaço físico para estudos. No que se refere à circulação foi sugerida a ampliação do prazo de empréstimo e a redução do prazo de reserva.

Com relação à questão 27 do questionário, também aberta, onde se perguntou o que gostariam que não mudasse na biblioteca. No total, oito respostas se referiram aos servidores e/ou estagiários, três usuários elogiaram o uso do sistema eletrônico. Também se referiram à climatização e a disposição para buscar atividades de apoio a atividadefim da instituição. 


\section{Considerações finais}

Pesquisas recentes mencionam a necessidade de informação de especialistas na área jurídica como, por exemplo, Silva (2010) que estudou a comportamento informacional dos advogados da região de Marília, em São Paulo, Brasil. Os resultados dessa pesquisam mostraram que as fontes mais utilizadas por aqueles profissionais são os livros e os colegas de profissão, neste último através de uma conversa informal para troca e obtenção de informações. As fontes disponíveis em seus escritórios são livros e a internet para obter informação jurídica atual. De certa maneira, os resultados aqui mencionados estão conformidade com os da pesquisa conduzida por Silva (2010).

O presente estudo será um valioso instrumento de suporte para a gestão da Biblioteca Professor Everardo da Cunha Luna. Pelo fato de ser o primeiro estudo dessa natureza na Procuradoria e poderá ser utilizado para nortear várias decisões no âmbito da gestão, do desenvolvimento de coleções e no atendimento aos seus usuários.

A pesquisa mostrou que os usuários da biblioteca da Procuradoria usam o acervo principalmente para embasar suas atividades no trabalho e a maioria afirmou freqüentá-la uma vez por semana. Mostrou-se evidente o uso do acervo de doutrina em livros muito superior à doutrina em periódicos. Esses resultados podem demonstrar desconhecimento por parte dos usuários desse material e do uso adequado das fontes de informação disponíveis para o Ministério Público Federal.

A baixa freqüência dos servidores a biblioteca pode estar relacionada ao caráter mais técnico das suas necessidades de informação. No entanto é interessante a proposta de realização de novos estudos para identificar as necessidades desses usuários potenciais que poderiam dizer até mais sobre a biblioteca que os usuários assíduos.

Os resultados revelaram uma intensa preferência dos usuários por fontes eletrônicas, especialmente a internet e as bases de dados on-line. Evidenciou-se inclusive que muitos só procuram a biblioteca após pesquisarem na internet. Ficou claro que os usuários possuem autonomia nas suas consultas e estão bem cientes das suas necessidades de informação.

Conclui-se, portanto, que o usuário da informação jurídica é cada vez mais exigente em suas consultas, apenas procurando a biblioteca quando recorreu a diversas fontes tais como: pesquisa na internet, acervo particular e consulta a colegas de profissão. Ou seja, as pesquisas recebidas na biblioteca geralmente possuem um grau de dificuldade mais elevado, pois já passaram por buscas prévias realizadas pelo usuário. $O$ atendimento e os recursos humanos receberam uma avaliação positiva, mas o meio ambiente da unidade recebeu críticas quanto à acústica e o espaço físico.

Os estudos de usuários devem ser realizados com uma freqüência constante nas unidades de informação visando acompanhar a evolução das áreas do conhecimento a que estas pertencem. Considerando a dinâmica do ciclo produtivo do conhecimento jurídico no Brasil bem como o uso cada vez maior de novas tecnologias da informação pelos usuários da informação jurídica, o intervalo de realização desses estudos não deveria ultrapassar dois anos.

Sabe-se que o nível de excelência na qualidade dos acervos jurídicos chega a ser utópico no panorama das instituições públicas brasileiras, em face não apenas da velocidade com que a informação jurídica se modifica em pouco tempo como também das amarras legais do processo de aquisição vigente para os órgãos públicos. Para isso o usuário tem muito a contribuir através do incentivo a dar sua opinião no processo de melhoria das unidades de informação jurídica. 


\section{Bibliografia}

Choo, C. W. (2006). A organização do conhecimento: como as organizações usam a informação para criar significado, construir conhecimento e tomar decisões. São Paulo: Senac.

Dias, M. M. K., \& Pires, D. (2004). Usos e usuários da informação. São Carlos: EdUFSCar.

Figueiredo, N. M. (1994). Estudos de uso e usuários da informação. Brasília: IBICT.

Nascimento, M. de J., \& Weschenfelder, S. (2002). Necessidade de informação dos vereadores de Florianópolis: estudo de usuário. Informação \& Sociedade: estudos. 12(1), 321-343. Recuperado em 13 outubro, 2010 de

http://www.ies.ufpb.br/ojs2/index.php/ies/article/view/161/155.

Passos, E., \& Barros, L. V. (2009). Fontes de informação para a pesquisa em direito. Brasília: Briquet de Lemos/Livros.

Sanz Casado, E. (1994). Manual de estudios de usuarios. Madrid: Fundación Germán Sánchez Ruipérez.

Silva, M. V. (2010). O comportamento informacional de advogados: um estudo com profissionais que atuam na cidade de Marília e região. Dissertação de Mestrado, Faculdade de Filosofia e Ciências, Universidade Estadual Paulista, Marília, SP, Brasil.

\section{Dados dos autores}

\section{Fabio Assis Pinho}

Licenciado en Biblioteconomía y Ciencia de la Información por la Universidad Federal de São Carlos (Brasil). Maestro y Doctor en Ciencia de la Información por la Universidad Estadual Paulista - UNESP - Campus de Marília/SP (Brasil). Profesor Adjunto del Departamento de Ciencia de la Información de la Universidad Federal de Pernambuco (Brasil). Docente de los Cursos de Licenciatura de Biblioteconomía y Gestión de la Información y del Programa de Pos Grado (Master) en Ciencia de la Información.

fabiopinho@ufpe.br

\section{Ângela Maria da Silva Barbosa}

Licenciada en Biblioteconomía y Documentación por la Universidad Federal de Pernambuco. Especialista en Gestión y Tecnología de la Información por la Universidad Federal de Pernambuco. Jefa titular de la biblioteca de la Procuraduría Regional de la República 5ª Región - Brasil.

asilvabarbosa@hotmail.com

Recebido - Received: 2011-06-05

Aceito - Accepted: 2011-09-30

\section{(cc) BY-NC-ND}

This work is licensed under a Creative Commons Attribution-Noncommercial-No Derivative Works 3.0 United States License.

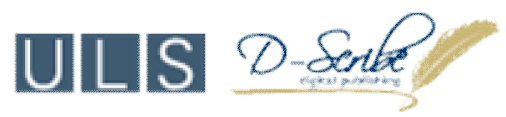

This journal is published by the University Library System of the University of Pittsburgh as part of its D-Scribe Digital Publishing Program and is cosponsored by the University of Pittsburgh Press. 